\title{
AN INEQUALITY FOR POLYNOMIALS WITH POSITIVE COEFFICIENTS AND APPLICATIONS IN RATIONAL APPROXIMATION
}

\author{
DANSHENG Yu* AND SONGPING ZHou
}

\begin{abstract}
We extend an inequality of Leviatan and Lubinsky ([3: Theorem 3.1]) to polynomials with positive coefficients. Two applications in approximation by rational functions with prescribed numerators are given.
\end{abstract}

Mathematics subject classification (2000): 41A20, 41A30.

Keywords and phrases: Inequality for polinomials, rational approximation.

\section{REFERENCES}

[1] R. A. DeVore, The approximation of continuous functions by positive linear operators, SpringerVerlag, 1972.

[2] R. A. DeVore and G. G. Lorentz, Constructive approximation, Springer-Verlag, 1993.

[3] D. LeViatan AND D. S. Lubinsky, Degree of approximation by rational functions with prescribed numerator degree, Canad. J. Math. 46 (1994), 619-633.

[4] X. F. MEI AND S. P. ZHOU, Approximation by reciprocals of polynomials with positive coefficients in $L_{[0,1]}^{1}$ space, Acta Math. Sinica 47 (2004), 1071-1078. (in Chinese)

[5] X. F. MeI AND S. P. ZHou, Approximation by rational functions with prescribed numerator degree in $L^{p}$ spaces for $1<p<\infty$, Acta Math. Hungar. 102 (2004), 305-319.

[6] X. F. MEI, The Jackson estimate of approximation by reciprocals of polynomials with positive coefficients in $L_{[0,1]}^{p}$ spaces for $1<p<\infty$ (to appear)

[7] G. Q. XU, The degree of approximation of real functions by reciprocals of polynomials with positive coefficients, J. Engin. Math. 13 (1996), 112-116. (in Chinese)

[8] Y. ZHAO AND S. P. ZHOU, Approximation by reciprocals of polynomials with positive coefficients in $L^{p}$ spaces, Acta Math. Hungar. 92 (2001), 205-217.

[9] S. P. ZHOU, Approximation by reciprocals of polynomials with positive coefficients, Southeast Asian Bull. Math. 28 (2004), 773-781. 